\title{
Preparation, Characterization, and Luminescence Properties of Orthorhombic Sodium Sulphate
}

\author{
Y. S. Vidya and B. N. Lakshminarasappa \\ Department of Physics, Jnana Bharathi Campus, Bangalore University, Bangalore 560 056, India \\ Correspondence should be addressed to B. N. Lakshminarasappa; bnlnarasappa@rediffmail.com
}

Received 15 October 2013; Revised 29 November 2013; Accepted 2 December 2013

Academic Editor: Lorenzo Pavesi

Copyright (c) 2013 Y. S. Vidya and B. N. Lakshminarasappa. This is an open access article distributed under the Creative Commons Attribution License, which permits unrestricted use, distribution, and reproduction in any medium, provided the original work is properly cited.

\begin{abstract}
A highly efficient thermoluminescence $\mathrm{Na}_{2} \mathrm{SO}_{4}$ phosphor with thenardite polymorphic structure was prepared by simple slow evaporation technique followed by subsequent calcination at $200^{\circ} \mathrm{C}, 400^{\circ} \mathrm{C}$, and $600^{\circ} \mathrm{C}$ for $4 \mathrm{~h}$ and the resultant crystals were characterized by various analytical techniques. All the samples exhibited thermodynamically stable thenardite phase and the grain growth was increased for the calcined samples. SEM analysis indicated the fine distribution of twinned orthogonal prism and pyramidal structure without any agglomeration. The electron spin resonance spectroscopy showed the existence of $\mathrm{SO}_{4}{ }^{-}$radicals as trap centre. The thermoluminescence behavior suggested the charge carrier recombination dynamics in the thenardite sample followed second-order kinetics. The trapping parameters such as activation energy $(E)$, order of kinetics $(b)$, and frequency factor $(s)$ have been determined using Chen's peak shape method. Further fading of the TL intensity of $\mathrm{Na}_{2} \mathrm{SO}_{4}$ showed that thenardite is quite suitable for radiation dosimetry even up to 15 days. The photoluminescence band of $\mathrm{Na}_{2} \mathrm{SO}_{4}$ reduced in its intensity after $\gamma$-irradiation, suggesting that defects are unstable and decay rapidly.
\end{abstract}

\section{Introduction}

Sulphates are attractive candidates in thermoluminescence (TL) dosimetry for the quantitative measurement of radiation dose. Due to high cost of the most popular TL dosimeters and also due to some competitions attending its reuse such as permanent radiation damage effects and the sensitivity to the annealing temperature much attention focused towards the innovation of new phosphor materials.

Sodium sulphate (thenardite), though very simple in chemical composition, has been the subject of various applications. It is used for the production of glasses and paints and for thermal energy storage techniques $[1,2]$. $\mathrm{Na}_{2} \mathrm{SO}_{4}$ exhibits a variety of phase transitions between its five anhydrous polymorphs (labelled I-V). The phase transformation sequence among the $\mathrm{Na}_{2} \mathrm{SO}_{4}$ polymorphs can be described as

$$
\mathrm{V} \stackrel{473 \mathrm{~K}}{\longleftrightarrow} \text { III } \stackrel{503 \mathrm{~K}}{\longleftrightarrow} \text { II } \stackrel{510 \mathrm{~K}}{\longleftrightarrow} \mathrm{I} \stackrel{1156 \mathrm{~K}}{\longleftrightarrow} \text { Melt }
$$

$\mathrm{Na}_{2} \mathrm{SO}_{4}$ forms two naturally occurring minerals mirabilite $\left(\mathrm{Na}_{2} \mathrm{SO}_{4}: 10 \mathrm{H}_{2} \mathrm{O}\right)$ and thenardite $\left(\mathrm{Na}_{2} \mathrm{SO}_{4}\right)$. Both are in thermodynamic equilibrium at $32^{\circ} \mathrm{C}$ which may be lowered to $18^{\circ} \mathrm{C}$ in the presence of foreign ions [3]. At room temperature phase $\mathrm{V}$ (thenardite) is reported to be stable while phase III is metastable. Phase I, and II are high-temperature polymorphs however, phase II is reported to have a narrow stability zone. Phase IV is considered to be metastable and its phase relation and structure have yet to be well established [4-7]. Correcher et al. observed the spectra of infrared-stimulated luminescence (IRSL), radioluminescence (RL), and TL of thenardite but they did not identify the origin of the luminescence center related to the IRSL, RL, and TL spectra of thenardite [8]. Sidike et al. studied the photoluminescence (PL) spectra, excitation spectra, and decay curves of natural, heat-treated and $\gamma$-irradiated thenardite from Ai-Diang salt lake, Xinjiang, China. From their studies they concluded that the origin of luminescence from their sample is mainly due to the crystal defects [9]. Reliable studies on the PL and TL properties of thenardite are very few to date, to the best of our knowledge.

In the present study, the fading, TL, and PL behavior of $\mathrm{Na}_{2} \mathrm{SO}_{4}$ phosphor are explained in detail. The phosphor 
material has been well characterized by powder X-ray diffraction (PXRD), scanning electron microscopy (SEM), Fouriertransform infrared spectroscopy (FTIR) and electron spin resonance spectroscopy techniques (ESR).

\section{Experimental}

2.1. Materials Preparation. $\mathrm{Na}_{2} \mathrm{SO}_{4}$ material was prepared by slow evaporation technique. For the crystallization experiments, based on the solubility data, sodium sulphate saturated solution with concentration of $50 \mathrm{~g} / 100 \mathrm{~mL}$ was prepared and filtered to remove any suspended particles. The fluid is transferred into 2 to $3,50 \mathrm{~mL}$ beakers and allowed to undergo slow evaporation. After 2 days the polycrystalline samples are obtained in the beaker which are collected, crushed, powdered, and calcined at $200^{\circ} \mathrm{C}, 400^{\circ} \mathrm{C}$, and $600^{\circ} \mathrm{C}$ for $4 \mathrm{~h}$ in furnace. The resultant powder was cooled and stored in dry place and pressed into pellets $\left(80 \mathrm{~kg} / \mathrm{cm}^{2}\right) . \mathrm{Na}_{2} \mathrm{SO}_{4}$ calcined at $400^{\circ} \mathrm{C}$ was used for the characterisation TL and PL measurements.

2.2. Material Characteristics. The PXRD pattern of sample is obtained using Philips PW/1050/70/76 X-ray diffractometer which was operated at $30 \mathrm{KV}$ and $20 \mathrm{~mA}$ using $\mathrm{CuK}_{\alpha}$ radiation as the source with a $\mathrm{Ni}$ filter at a scan rate of $2^{\circ} / \mathrm{min}$ and matched the standard data of ICDD card 371465 for synthetic thenardite $\mathrm{Na}_{2} \mathrm{SO}_{4}$. The PXRD peaks of crystal planes (002), (040), and (220) were selected to determine the lattice parameters and unit cell volume of $\mathrm{Na}_{2} \mathrm{SO}_{4}$. The size, shape, and distribution of the grains were examined by SEM analysis using Quanta-200 FEI SEM. FTIR studies of the sample were performed on a Perkin-Elmer FTIR spectrometer (Spectrum 1000) using KBr as reference standard.

ESR measurements were performed at RT with a Varian E-112 ESR spectrometer, SAIF, IIT Bombay, India, in a standard rectangular $X$-band microwave frequency $(9.5 \mathrm{GHz})$ with sensitivity of $5 \times 10^{10} \Delta \mathrm{H}$ spins. The field scan of $4 \mathrm{mT}$ has been selected to observe ESR lines near the free electron resonance $(g=2.00277)$.

TL glow curves were measured with system in the temperature range from 25 to $300^{\circ} \mathrm{C}$ operating with linear heating rates of $5 \mathrm{~K} / \mathrm{sec}$. Prior to the TL measurements, samples (pellets of $1 \mathrm{~mm}$ thickness with $5 \mathrm{~mm}$ in diameter are used for TL measurements) were exposed to $\gamma$-irradiation from a ${ }^{60}$ Co source to a total dose of $0.02 \mathrm{kGy}$ to $2 \mathrm{kGy}$ at the sample cavity. PL emission and excitation spectra were registered in identical experimental conditions, using Yvon Fluorometer, Jobspectrometer with Xenon lamp source at a excitation wavelength of $340 \mathrm{~nm}$ at SAIF, IIT Chennai, India.

\section{Results and Discussion}

3.1. Powder X-Ray Diffraction Analysis. Figure 1 shows the PXRD pattern of $\mathrm{Na}_{2} \mathrm{SO}_{4}$ calcined at different temperatures. The reflections pattern were indexed to phase $\mathrm{V}$ thenardite (ICDD card 37-1465).

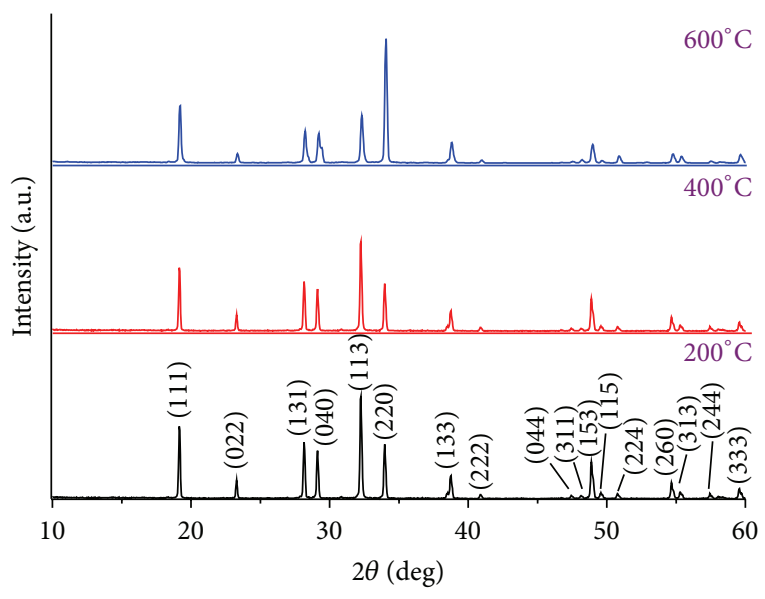

FIGURE 1: PXRD pattern of thenardite at different calcination temperatures.

It is well known that the calcination can improve the crystallinity of the samples. In order to investigate the possible crystallization process of thenardite by increasing the calcining temperature, XRD analyses were carried out on the samples calcined at $200^{\circ} \mathrm{C}, 400^{\circ} \mathrm{C}$, and $600^{\circ} \mathrm{C}$, respectively. The increase of calcination temperature results in the grain growth of sample due to nucleation in interaction between small crystallite which fuses to form larger particles. The average crystallite size $(D)$ and matrix distortion $(\varepsilon)$ are calculated from FWHM of the most intense PXRD peak using (2) and (3), respectively $[10,11]$,

$$
\begin{aligned}
& D=\frac{0.9 \lambda}{\beta \cos \theta}, \\
& \beta=4 \varepsilon \tan \theta,
\end{aligned}
$$

where " $D$ " is the average grain size of the crystallites, " $\lambda$ " is the incident wavelength, " $\theta$ " is the Bragg angle, " $\varepsilon$ " is the stress factor, and " $\beta$ " is the diffracted full width at half maximum (in radians) caused by the crystallites. As the calcination temperature increases from 200 to $600^{\circ} \mathrm{C}$, the crystallite size increases from 42 to $55 \mathrm{~nm}$ (Table 1).

The crystal structure of thenardite is shown in Figure 2.

Thenardite belongs to $F_{\text {ddd }}$ space group with octahedral structure of nearly regular $\mathrm{SO}_{4}$ tetrahedra and distorted $\mathrm{NaO}_{6}$ octahedra. The sodium atoms are each surrounded by 6 oxygen atoms each at $2.334 \AA, 2.426 \AA$, and $2.534 \AA$ forming distorted $\mathrm{NaO}_{6}$ octahedra with a two fold axis parallel to $c$ axis. The $\mathrm{O}-\mathrm{Na}-\mathrm{O}$ angles, $56.15^{\circ}-134.93^{\circ}$, are greatly distorted from octahedral symmetry $[12,13]$. All the sulphate ions are separated from each other by distances $>3 \AA$ for two oxygen atoms belonging to different sulphate groups. All S$\mathrm{O}$ distances are equal $(1.476 \pm 0.001 \AA)$; thus the sulphur atom is fixed in a special point position with 222 point symmetry. Each $\mathrm{SO}_{4}$ tetrahedron shares two of its edges with two different $2.534 \AA$ representing the distances to oxygen's forming the shared tetrahedral edge. The remaining corners of the $\mathrm{NaO}_{6}$ octahedron are shared with another four $\mathrm{SO}_{4}$ tetrahedron there giving a $3 \mathrm{D}$ framework $[12,13]$. 
TABLE 1: The crystallite size and stress factor for thenadrite calcined at different temperatures.

\begin{tabular}{lccc}
\hline Calcined temperature $\left({ }^{\circ} \mathrm{C}\right)$ & Crystallite size $(\mathrm{nm})$ & $2 \theta$ (degrees) & Stress factor $(\varepsilon)$ \\
\hline 200 & 42 & 34.07 & 0.163 \\
400 & 49 & 32.28 & 0.146 \\
600 & 55 & 32.13 & 0.059 \\
\hline
\end{tabular}

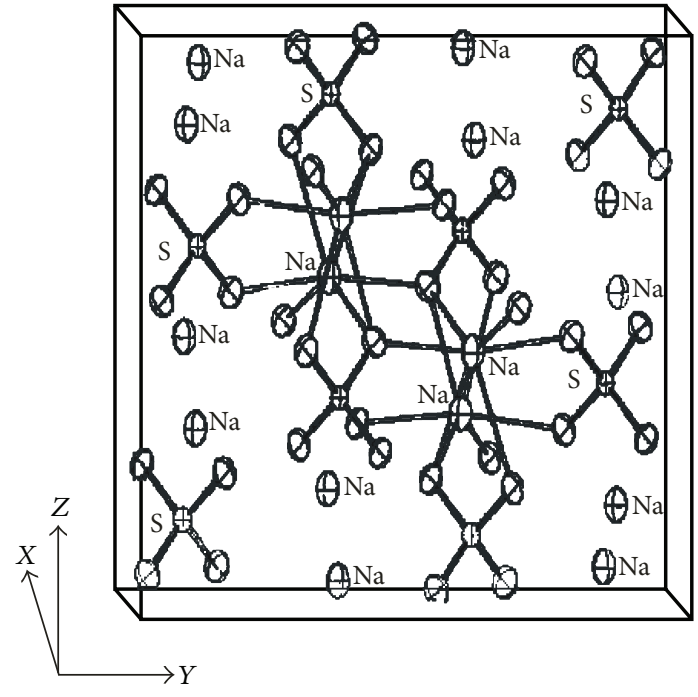

FIGURE 2: Crystal structure of $\mathrm{Na}_{2} \mathrm{SO}_{4}$.

Mirabilite (phase III) also has an orthorhombic crystal structure with space group $C_{\mathrm{mcm}}$. Its cell parameters are $a=$ $7.038 \AA, b=9.043 \AA, c=5.785 \AA$, and $\alpha=\beta=\gamma=$ $90^{\circ}$ [14]. The average calculated S-O band length is $1.478 \AA$. There are two different types of sodium atoms in the phase III bulk structure, giving five different $\mathrm{Na}-\mathrm{O}$ distances, which are found to be $2.46,2.37,2.29,2.54$, and $2.86 \AA$ [15]. The relative lattice energies of phases III and $\mathrm{V}$ are $-548.91 \mathrm{eV}$ and $-1097.97 \mathrm{eV}$, respectively. Due to the lower lattice energy, $\mathrm{Na}_{2} \mathrm{SO}_{4}$ nucleates in thenardite form predominantly in solution phase attributed to thermodynamic constraints.

3.2. Scanning Electron Microscopy Studies. The SEM picture of as-prepared thenardite is shown in Figure 3.

The material showed that the generalized hexagonal habit of grains corresponds to twinned orthorhombic prisms and pyramids without any agglomeration. All the thenardite crystals are distributed uniformly.

3.3. FTIR Studies. FTIR spectrum was measured to check the purity of the synthesized phosphor material. Figure 4 gives the IR spectra of thenardite calcined at different temperature in the range of $400-4000 \mathrm{~cm}^{-1}$.

In the obtained spectra, it is possible to distinguish clearly the ranges corresponding to the vibrations of the $\mathrm{SO}_{4}{ }^{2-}$ group and the $\mathrm{Na}-\mathrm{O}$ vibrations (Table 2).

The most intense bands due to stretching and bending of $\mathrm{S}-\mathrm{O}$ bond are situated at 1100 and $600 \mathrm{~cm}^{-1}$, respectively.

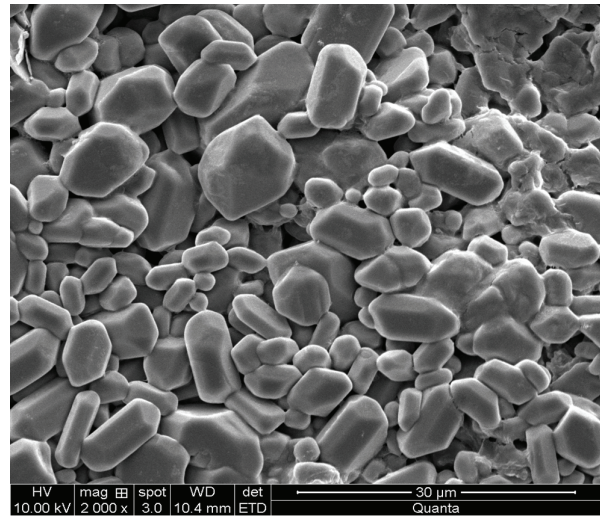

FIgURE 3: SEM image of $\mathrm{Na}_{2} \mathrm{SO}_{4}$ calcined at $400^{\circ} \mathrm{C}$.

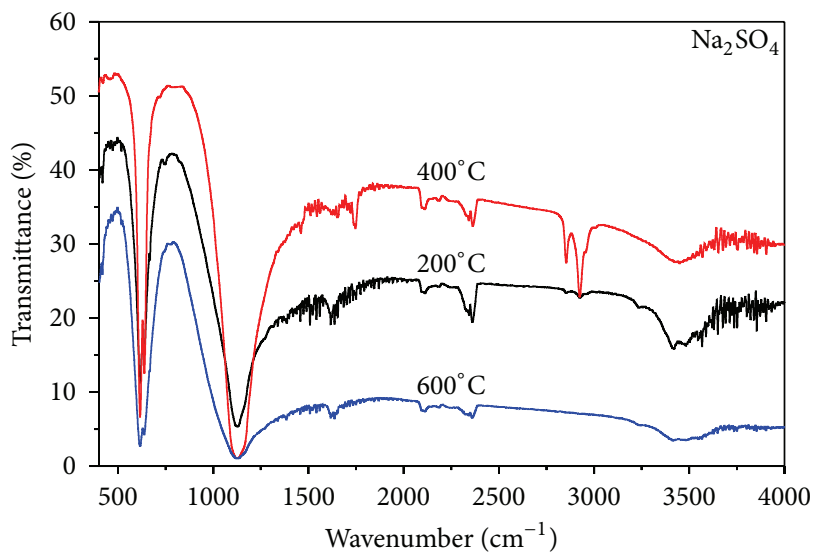

FIGURE 4: FTIR spectra of thenardite calcined at different calcination temperatures.

TABLE 2: The characteristic FTIR spectra of $\mathrm{Na}_{2} \mathrm{SO}_{4}$.

\begin{tabular}{lccc}
\hline \multirow{2}{*}{ Nature of Bond } & \multicolumn{3}{c}{ IR absorption peak $\left(\mathrm{cm}^{-1}\right)$} \\
& $200^{\circ} \mathrm{C}$ & $400^{\circ} \mathrm{C}$ & $600^{\circ} \mathrm{C}$ \\
\hline \multirow{3}{*}{$\mathrm{M}-\mathrm{O}$} & 2847 & 2854 & - \\
& 2921 & 2921 & - \\
& 3415 & 3444 & 3422 \\
\hline \multirow{2}{*}{$\mathrm{S}-\mathrm{O}$} & 613 & 613 & 616 \\
& 1117 & 1129 & 1121 \\
\hline
\end{tabular}

3.4. Electron Spin Resonance Studies. Unirradiated $\mathrm{Na}_{2} \mathrm{SO}_{4}$ samples gave no ESR signals even by applying $5 \mathrm{~mW}$ power. The ESR spectrum of $\mathrm{Na}_{2} \mathrm{SO}_{4}$ recorded at RT after $\gamma$ irradiation is typical powder spectra of spin $1 / 2$ paramagnetic centres with anisotropic $g$-value (Figure 5). 


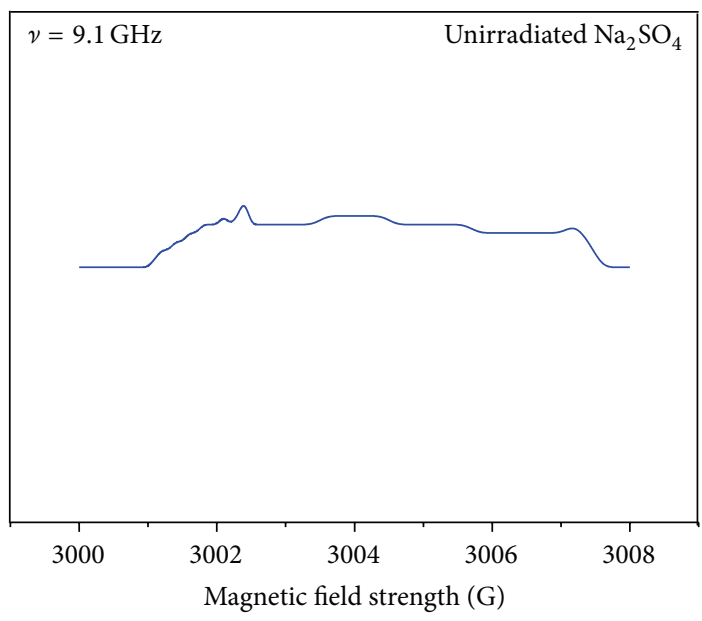

(a)

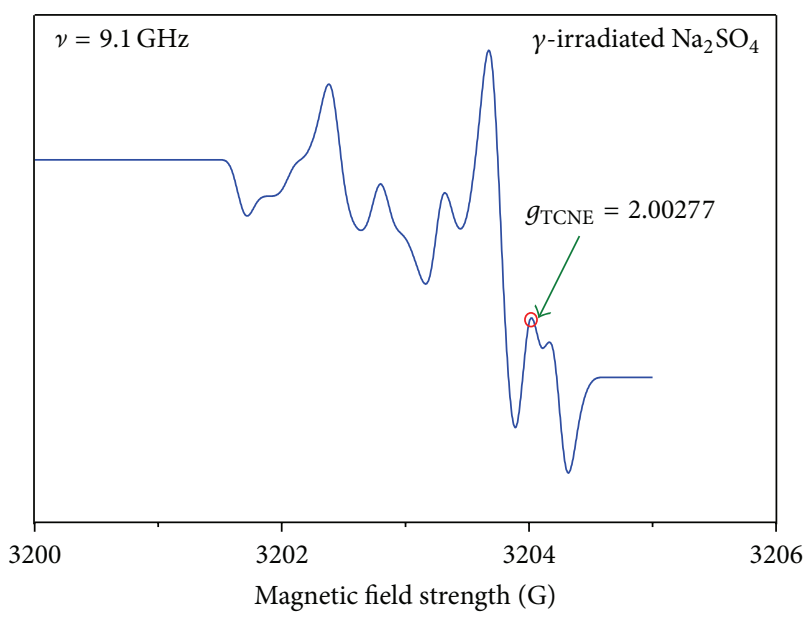

(b)

FIGURE 5: ESR spectra of (a) unirradiated and (b) $\gamma$-irradiated $\mathrm{Na}_{2} \mathrm{SO}_{4}$ calcined at $400^{\circ} \mathrm{C}$ recorded at RT.

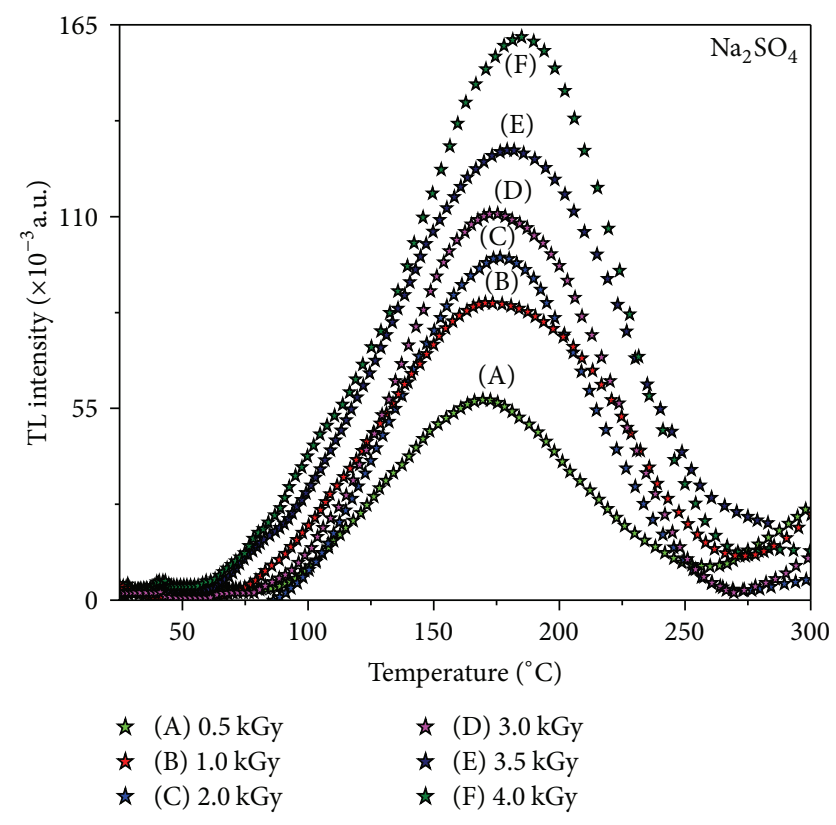

Figure 6: TL glow curves of $\gamma$-irradiated $\mathrm{Na}_{2} \mathrm{SO}_{4}(0.025 \mathrm{kGy}-$ $4 \mathrm{kGy}$ ) calcined at $400^{\circ} \mathrm{C}$.

The ESR line close and to the left of TCNE marker is due to defect centre. The field scan has been selected to observe ESR lines near the free electron resonance $(g=$ 2.00277). The powder spectra are difficult to interpret since hyperfine structure is not observed. A possibility is to make the comparison with other similar compounds. As already known, the most probable radiation products in sulphates are $\mathrm{SO}_{3}{ }^{-}$and $\mathrm{SO}_{4}{ }^{-}$radicals $[16,17]$. In the present case this is mainly $\mathrm{SO}_{4}{ }^{-}$, probably formed by natural $\gamma$-irradiation as

$$
\mathrm{SO}_{4}{ }^{2-} \stackrel{\gamma \text {-irradiation }}{\longrightarrow} \mathrm{SO}_{4}^{-}+\mathrm{e}^{-}
$$

The observed principal $g$-values are $g_{\|}=2.030$ and $g_{\perp}=$ 2.0090 .

Comparing the obtained $g$-values of signals with those of $\mathrm{SO}_{3}{ }^{-}$and $\mathrm{SO}_{4}{ }^{-}$in the literature, it is reasonable to relate the signal to the $\mathrm{SO}_{4}{ }^{-}$radical. $[18,19]$. The slight differences among published and measured $g$-values may arise from difference in distortion of the molecular structure or in lattice environment of the radicals.

3.5. Thermoluminescence Studies. The TSL glow curves of thenardite sample were recorded at RT for different $\gamma$-ray irradiation from 0.25 to $4 \mathrm{kGy}$ (Figure 6).

The sample has one glow peak at temp $\sim 180^{\circ} \mathrm{C}$ indicating that only unit set of trap states is being activated within the particular temperature range with its own value of activation energy $\left(E_{q}\right)$ and frequency factor $(s)$ and is slightly shifted towards higher temperature side as the $\gamma$-ray dose increases accompanied by the intensification of the peak. The increase in thermal fluctuation enhances the defect sites which enhance the overall heat content of the solid, which might probably shift the TL peak slightly towards higher temperature.

Thorough investigation on the TL mechanism using ESR shows that, among all the formed centres, the $\mathrm{SO}_{4}{ }^{-}$ion appears to play an important role throughout the temperature range of TL $[20,21]$. Nambi et al. concluded that the nature of the traps involved in TSL is the same as indicated in the ESR spectra on the basis of parallelism exhibited by (i) gamma dose against ESR and TSL signals build-up curves and (ii) RT decay curves of ESR and TSL intensities [22]. The TL peak appearing at $453 \mathrm{~K}$ may be caused by the charges released from the $\mathrm{SO}_{4}{ }^{-}$centre. Since the defect centre $\mathrm{SO}_{3}{ }^{-}$decays completely at $573 \mathrm{~K}$, no TL role could be specifically assigned to this centre.

The increase in the intensities of the glow peaks with increase of radiation dose can be understood by the fact that more and more traps are responsible for these glow peaks and were getting filled with the increase of irradiation dose and 


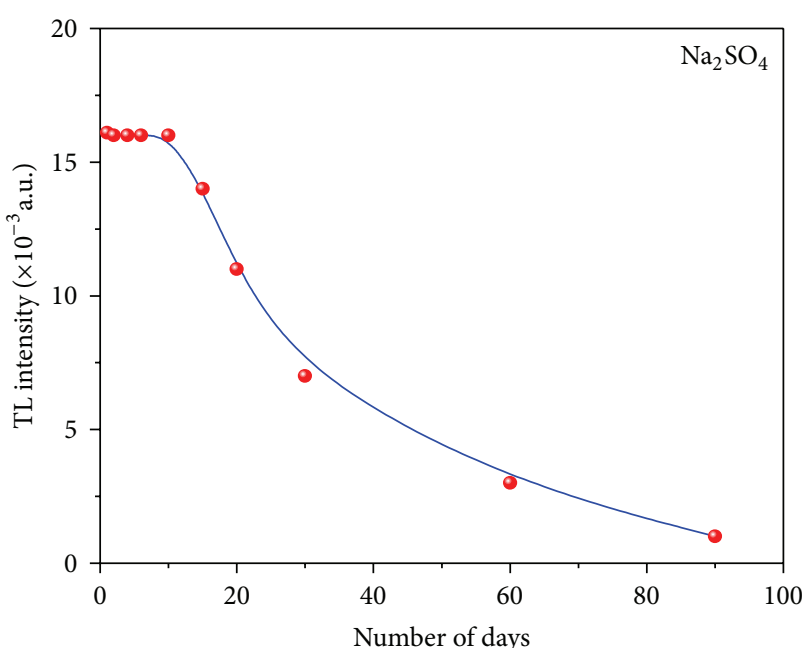

FIGURE 7: TL fading of thenardite calcined at $400^{\circ} \mathrm{C}$ exposed to $2 \mathrm{kGy}$ of gamma irradiation for a period of 3 months.

subsequently these traps release the charge carriers on thermal stimulation to finally recombine with their counterparts, thus giving rise to intense glow peaks.

3.5.1. TL Fading. Fading is the unintentional loss of the TL signal and may be caused by optical stimulation. Thermal fading originates from the fact that even at room temperature there is a certain probability of charge carriers escaping from their trapping centres. In general, high-sensitivity materials should be handled carefully and stored in opaque containers to prevent its fading from light exposure. Other types of fading, which are not temperature dependent, are caused by quantum mechanical tunneling of the trapped charge to recombination sites and transitions between localized states, that is, transitions that do not take place via the delocalized bands [23].

Initially, the high fading effect of gamma-irradiated samples is due to the recombination of the trapped electrons released at room temperature. After initial fading the sample becomes stable, and new recombination can occur only by heating the sample at elevated temperatures. The effect was studied by irradiating samples with a gamma dose of $2 \mathrm{kGy}$. One of these irradiated samples was measured immediately (1h) after irradiation to be considered as a reference. The other samples irradiated with the same dose have been stored at room temperature and the TL signal was recorded at different intervals for nearly 90 days (Figure 7).

About $1.2 \%$ fading is observed during the first five days, but thereafter the intensity remained almost constant. However, it is suggested that the irradiation of thenardite phosphor at high doses results in the formation of deep traps which resulted in the fading of TL signal.

Thenardite has been tested for its reusability. The thenardite material was given exposure of $1 \mathrm{kGy}$ and a TL glow curve was recorded up to $573 \mathrm{~K}$. It was then quickly cooled to RT by switching off the heater and drawing it out of the sample holder. It was again given the same exposure and

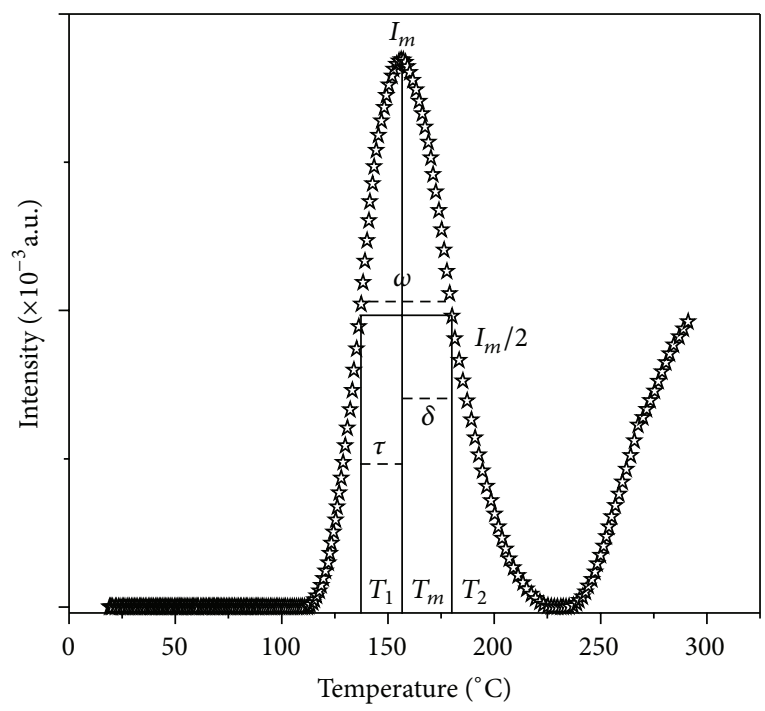

FIGURE 8: Representative diagram of different quantities used in the glow-curve shape method.

the glow curve recording was performed. No change in the intensity of the peak was observed. The cycle was repeated five times with the same sample, but no change in the glow curve structure or the shape was observed. Since the sensitivity of a phosphor did not change after several cycles of exposure and readouts, it can be concluded that the prepared phosphors are obviously desirable for dosimetric applications.

\subsubsection{Analysis of TL Glow Curve and Calculation of Trapping} Parameters. The trap parameters, such as activation energy and order of kinetics, were calculated for the $430 \mathrm{~K}$ glow peak of the thenardite phosphor irradiated with a gamma dose of $2 \mathrm{kGy}$ at RT using the Chen's set of empirical formulae for the shape of the glow curve [24]. The order of the kinetics can be found by the form factor $\left(\mu_{q}\right)$. A representative diagram of different quantities used in the glow-curve shape method while determining the trap parameters is shown in Figure 8. Theoretically, a value of the geometrical form factor which is close to 0.42 implies first-order kinetics and a value of 0.52 is for second-order kinetics. In the present study, its value lies in the range of $0.48-0.52$, suggesting second-order kinetics. This suggests that TL emission involves retrapping of charges. The activation energy $\left(E_{g}\right)$, frequency factor $(s)$, and order of kinetics can be estimated using the following relations:

$$
E_{\alpha}=C_{\alpha}\left(\frac{K T_{m}^{2}}{\alpha}\right)-b_{\alpha}\left(2 K T_{m}\right)
$$

where $\alpha=\tau, \omega, \delta ; \omega=T_{2}-T_{1} ; \delta=T_{2}-T_{m} ; \tau=T_{m}-T_{1}$

$$
\begin{aligned}
& C_{\tau}=1.51+3.0\left(\mu_{g}-0.42\right) \\
& b_{\tau}=1.58+4.2\left(\mu_{g}-0.42\right)
\end{aligned}
$$


TABLE 3: Kinetic parameters for the $\mathrm{Na}_{2} \mathrm{SO}_{4}$ irradiated at different $\gamma$-ray doses.

\begin{tabular}{lccc}
\hline$\gamma$-Ray dose (K Gy) & $T_{\max }\left({ }^{\circ} \mathrm{C}\right)$ & $E_{g}(\mathrm{eV})$ & $s\left(\mathrm{~s}^{-1}\right)$ \\
\hline 0.25 & 170 & 0.18 & $0.63 \times 10^{12}$ \\
1.00 & 172 & 0.17 & $0.91 \times 10^{12}$ \\
2.00 & 174 & 0.19 & $1.24 \times 10^{12}$ \\
3.00 & 176 & 0.20 & $6.28 \times 10^{12}$ \\
3.50 & 180 & 0.18 & $7.04 \times 10^{12}$ \\
4.00 & 185 & 0.17 & $7.16 \times 10^{12}$ \\
\hline
\end{tabular}

$T_{\max }, E_{g}$, and $s$ are the maximum TL glow peak temperature, activation energy, and frequency factor of the $\mathrm{Na}_{2} \mathrm{SO}_{4}$, respectively.

$$
\begin{gathered}
C_{\delta}=0.976+7.3\left(\mu_{g}-0.42\right) ; \quad b_{\delta}=0, \\
C_{\omega}=2.52+10.2\left(\mu_{g}-0.42\right) ; \quad b_{\omega}=1, \\
\mu_{g}=\frac{T_{2}-T_{m}}{T_{2}-T_{1}}, \\
s=\left(\frac{\beta E}{k T m^{2}}\right)\left(\frac{\exp \left(E / k T_{m}\right)}{1+(b-1)\left(2 k T_{m} / E\right)}\right),
\end{gathered}
$$

where $k$ is the Boltzmann constant $t=8.6 \times 10^{-5}$.

The frequency factor is known as the attempt-to-escape frequency and is interpreted as the number of times per second that an electron interacts with the crystal lattice of a solid multiplied by transition probability and the change in entropy associated with the transition from a trap to the delocalized band. The expected maximum value of " $s$ " should be similar to the lattice vibrational frequency, that is, $10^{12}-10^{14} \mathrm{~s}^{-1}$. This frequency factor describes the trap as a potential well and " $s$ " should be the product between the frequency with which the trapped electrons strike the wells of the potential barrier and the reflection coefficient. Thus " $s$ " should be expected to be about of the order of the vibrational frequency of the crystal. Table 3 lists the peak parameters for the thenardite irradiated at different dose of $\gamma$-ray exposure. With increase in the dose of $\gamma$-ray exposure, the activation energy remains almost the same whereas the frequency factor increases which indicates the increase in vibrational frequency of the crystal lattice.

3.6. Excitation and Photoluminescence Studies of Sodium Sulphate. Optical absorption spectra of thenardite powder sample show a broad absorption bands (Figure 8). The absorption peaks occurring at $237 \mathrm{~nm}$ were attributed to the $\mathrm{SO}_{4}{ }^{-}$radical. The shoulder at $247 \mathrm{~nm}$ and the peak at $262 \mathrm{~nm}$ were attributed to absorption by $\mathrm{SO}_{3}{ }^{-}$radical.

A PL spectrum of thenardite was attributed to several levels of physical origins: oxygen vacancies, self-trapped excitons, surface states, and localized excitons, and so forth. The electrons and holes in thenardite react with electron donors or acceptors and undergo desired redox reactions. Therefore, generation and relaxation dynamics of electrons and holes are crucial in determining the overall efficiency of

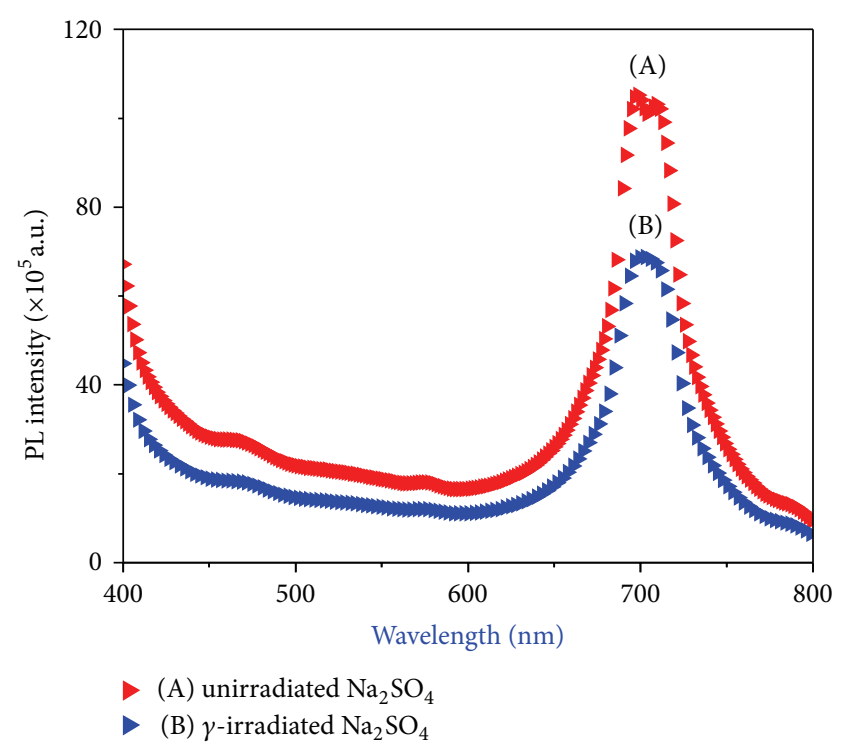

Figure 9: Photoluminescence spectra of $\mathrm{Na}_{2} \mathrm{SO}_{4}$ calcined at $400^{\circ} \mathrm{C}$ $\left(\lambda_{\mathrm{ex}}=340 \mathrm{~nm}\right)$.

luminescence process. Recombination processes are actually a vital factor that determines the luminescence performance of phosphor material.

Thenardite is a fluorescent mineral, showing white luminescence under short wave ultraviolet (UV) light and milkwhite luminescence under long wave UV light and long phosphorescence [25].

Figure 9 shows the photoluminescence spectrum of $\mathrm{Na}_{2} \mathrm{SO}_{4}$ upon $340 \mathrm{~nm}$ excitation. The PL emission spectrum shows that an intense peak at $\sim 702 \mathrm{~nm}$ is attributed to excitonic PL arising from intrinsic defects of thenardite. This emission band showed a distinct vibronic structure. The vibronic structure is the characteristic of $\mathrm{S}^{2-}$ centre which was observed in the red region. This suggests that the origin of the luminescence from thenardite is due to $\mathrm{S}^{2-}$ centre. The emission and excitation spectra due to the $\mathrm{S}^{2-}$ centre in synthetic $\mathrm{Na}_{2} \mathrm{SO}_{4}, \mathrm{~K}_{2} \mathrm{SO}_{4}$, and $\mathrm{Rb}_{2} \mathrm{SO}_{4}$ were observed by some researchers [26-28]. Kushunirenko et al. observed luminescence due to $\mathrm{S}^{2-}$ in $\mathrm{Na}_{2} \mathrm{SO}_{4}$ at 300,77 , and $4.2 \mathrm{~K}$ under $337.1 \mathrm{~nm}$ excitation. The emission band with the most intense peak at $\sim 600 \mathrm{~nm}$ showed a distinct vibronic structure which is evident even at RT [26]. Belyi et al. prepared synthetic crystals of $\mathrm{Na}_{2} \mathrm{SO}_{4}: \mathrm{S}$ and $\mathrm{Na}_{2} \mathrm{SO}_{4}: \mathrm{S}, \mathrm{Ca}^{2+}$ by heating a mixture of $\mathrm{Na}_{2} \mathrm{SO}_{4}$, and sulphur and $\mathrm{CaCl}_{2}$ at $1000^{\circ} \mathrm{C}$ for $2 \mathrm{~h}$ [28]. They observed an emission band with a distinct vibronic structure, whose most intense peak was located at $\sim 600 \mathrm{~nm}$ under $337.1 \mathrm{~nm}$ excitation at $4.2 \mathrm{~K}$ and excitation bands with peaks at about $330 \mathrm{~nm}$ and $400 \mathrm{~nm}$ by monitoring luminescence at $680 \mathrm{~nm}$ at $4.2 \mathrm{~K}$.

The $\gamma$-ray irradiated thenardite reduced the intensity of almost all the absorption bands which shows that the intrinsic defects are unstable and decay rapidly. Similarly, they did not change the feature of the PL but reduced the luminescence efficiency. This suggests that the $\gamma$-ray irradiation of thenardite may generate a killer centre for 
luminescence in thenardite. We could not find any dip due to absorption by the killer centre. It seems that $\gamma$-ray irradiation has an annealing effect although mechanism is not yet clear.

\section{Conclusions}

$\mathrm{Na}_{2} \mathrm{SO}_{4}$ phosphor has been prepared at RT by slow evaporation technique. PXRD pattern showed the presence of an orthorhombic phase while SEM studies showed the presence of uniform distribution of twinned orthorhombic prisms and pyramids. The study of TL characteristics shows that the phosphor exhibits good linearity, low fading, and reusability. An ESR study confirms that $\mathrm{SO}_{4}{ }^{-}$defect centre is responsible for TL glow peak. The PL peaks arise from $\mathrm{S}^{2-}$ centres of $\mathrm{Na}_{2} \mathrm{SO}_{4}$ and the $\gamma$-ray irradiated of thenardite did not change the features of the PL spectra. Fading and reusability test revealed that the prepared phosphor is quite stable up to 15 days and therefore has potential for the use in radiation dosimetry.

\section{References}

[1] J. P. Elder, "Thermal energy storage materials-a DSC study," Thermochimica Acta, vol. 36, no. 1, pp. 67-77, 1980.

[2] H. G. Wiedemann, "Thermal studies on thenardite," Thermochimica Acta, vol. 50, no. 1-3, pp. 17-29, 1981.

[3] O. Braitsh, Entstehung, and K. S. D. Salzlagerstallen Springer, NewYork, NY, USA, 1962.

[4] S. Gomathy, P. Gopalan, and A. R. Kulakarni, "Effect of Homovalent anion doping on the conductivity and phase transitions in $\mathrm{Na}_{2} \mathrm{SO}_{4}$," Journal of Solid State Chemistry, vol. 146, no. 1, pp. 6-12, 1999.

[5] F. C. Kracek and R. E. Gibson, "The polymorphism of sodium sulfate: III. Dilatometer investigations," Journal of Physical Chemistry, vol. 34, no. 1, pp. 188-206, 1930.

[6] B. K. Choi, H. K. Lee, and Y. W. Kee, "Ionic conduction and structural phase transitions of $\mathrm{Na}_{2} \mathrm{SO}_{4}$ doped with various impurities," Solid State Ionics, vol. 113-115, pp. 493-499, 1998.

[7] C. R. Navarro, E. Doehne, and E. Sebastian, "How does sodium sulfate crystallize? Implications for the decay and testing of building materials," Cement and Concrete Research, vol. 30, no. 10, pp. 1527-1534, 2000.

[8] V. Correcher, J. Garcia-Guinea, P. Lopez-Arce, and J. M. GomezRos, "Luminescence emission spectra in the temperature range of the structural phase transitions of $\mathrm{Na}_{2} \mathrm{SO}_{4}$," Spectrochimica Acta A, vol. 60, no. 7, pp. 1431-1438, 2004.

[9] A. Sidike, K. Niyazi, H. Zhu, K. Atobe, and N. Yamashita, "Photoluminescence properties of thenardite from Ai-Ding Salt Lake, Xinjiang, China," Physics and Chemistry of Minerals, vol. 36, no. 3, pp. 119-126, 2009.

[10] H. C. Freiheit, "Order parameter behaviour and thermal hysteresis at the phase transition in the superionic conductor lithium sodium sulfate $\mathrm{LiNaSO}_{4}$," Solid State Communications, vol. 119, no. 8-9, pp. 539-544, 2000.

[11] A. Choubey, S. K. Sharma, S. P. Lochab, and D. Kanjilal, "Effect of ion irradiation on the thermoluminescence properties of $\mathrm{K}_{2} \mathrm{Ca}_{2}\left(\mathrm{SO}_{4}\right)_{3}$ phosphor," Radiation Effects and Defects in Solids, vol. 166, no. 7, pp. 487-500, 2011.
[12] A. G. Nord, "Refinement of the crystal structure of thenardite, $\mathrm{Na}_{2} \mathrm{SO}_{4}(\mathrm{~V})$," Acta Chemica Scandinavica, vol. 27, pp. 814-822, 1973.

[13] F. C. Hawthorne and R. B. Ferguson, "Anhydrous sulphates. I: refinement of the crystal structure of celestite with an appendix on the structure of thenardite," The Canadian Mineralogist, vol. 13, pp. 181-187, 1975.

[14] W. Eysel, "Christal chemistry of the system $\mathrm{Na}_{2} \mathrm{SO}_{4}-\mathrm{K}_{2} \mathrm{SO}_{4}$ $\mathrm{K}_{2} \mathrm{CrO}_{4}-\mathrm{Na}_{2} \mathrm{CrO}_{4}$ and the glaserite phase," American Mineralogist, vol. 58, pp. 736-747, 1973.

[15] K. Tanaka, H. Naruse, H. Morikawa, and F. Marumo, "Phasetransition process of $\mathrm{Na}_{2} \mathrm{SO}_{4}$ (III) to $\mathrm{Na}_{2} \mathrm{SO}_{4}(\mathrm{I})$ and anharmonic thermal vibration," Acta Crystallographica B, vol. 47, pp. 581$588,1991$.

[16] O. Braitsh, Entstehung, and K. S. D. Salzlagerstallen, Theory of Magnetic Resonance, Springer, New York, NY, USA, 2nd edition, 1962.

[17] R. Huzimura and K. Atarachi, "The role of sulphur-oxy radicals in thermoluminescence and exoelectron emission of $\mathrm{CaSO}_{4}$, phosphors," Physica Status Solidi (A), vol. 70, no. 2, pp. 649-657, 1982.

[18] C. L. P. Mauricio, E. Bortolin, and S. Onori, "ESR study of $\mathrm{CaSO}_{4}$ :Dy TLD," Radiation Measurements, vol. 26, no. 4, pp. 639-644, 1996.

[19] T. K. Gundu Rao, B. C. Bhatt, J. K. Srivastava, and K. S. V. Nambi, "On the sulphoxy radicals in $\mathrm{CaSO}_{4}: \mathrm{Dy}, \mathrm{Na}$ thermoluminescent phosphor: electron paramagnetic resonance studies," Journal of Physics, vol. 5, no. 12, pp. 1791-1800, 1993.

[20] V. Natarajan, T. K. Seshagiri, R. M. Kadam, and M. D. Shastri, " $\mathrm{SO}^{4-}-\mathrm{SO}^{3-}$ radical pair formation in $\mathrm{Ce}$ doped and $\mathrm{Ce}, \mathrm{U}$ co-doped $\mathrm{K}_{3} \mathrm{Na}\left(\mathrm{SO}_{4}\right)_{2}$ : EPR evidence and its role in TSL," Radiation Measurements, vol. 35, no. 4, pp. 361-368, 2002.

[21] T. Hayakawa and M. Ohta, "Role of dopant on the formation of $\mathrm{SO}^{3-}$ radical induced by X-ray irradiation in $\mathrm{K}_{3} \mathrm{Na}\left(\mathrm{SO}_{4}\right)_{2}$ crystals," Journal of Luminescence, vol. 81, no. 4, pp. 313-319, 1999.

[22] K. S. V. Nambi, V. N. Bapat, and A. K. Ganguly, "Thermoluminescence of $\mathrm{CaSO}_{4}$ doped with rare earths," Journal of Physics C, vol. 7, no. 23, Article ID 4403, 1974.

[23] M. Magharbi and D. E. Arafah, "Sensitization of the thermoluminescence response of $\mathrm{CaF}_{2}$ phosphors ," Physica Status Solidi (A), vol. 195, no. 2, pp. 459-467, 2003.

[24] R. Chen and Y. Kirish, Analysis of Thermally Stimulated Processes, Pergamon, New York, NY, USA, 1981.

[25] I. Y. Kushnirenko, S. G. Nedelko, and N. P. Smoyar, "Spectral behavior of electron-oscillations in luminescence centres of alkali metals activated by molecular anions $\mathrm{S}_{2}^{-}$," Ukrainakii Flzicheakil Zhurnal, vol. 35, p. 855, 1990.

[26] D. N. Govorun, I. Y. Kushunirenko, S. G. Nedel'ko, V. P. Sakun, and N. P. Smoyar, "Luminescent properties of $\mathrm{S}_{2}^{-}$impurity molecular anions in $\mathrm{Rb}_{2} \mathrm{SO}_{4}$ crystals," Zhurnal Prikladnoi Spektroskopii, p. 930, 1990.

[27] S. G. Nedel'ko, M. M. Podshivailov, N. P. Smoyar, and V. I. Shelud'ko, "Vibronic interactions in luminescent impurity centers "molecular anion-defect" in ionic and heterodesmic crystals," Zhurnal Prikladnoi Spektroskopii, vol. 55, p. 836, 1991.

[28] M. U. Belyi, S. G. Nedel'ko, and V. I. Shelud'ko, "Luminescence of alkali metal sulfate crystals with sulfur impurity," Zhurnal Prikladnoi Spektroskopii, vol. 61, p. 283, 1994. 

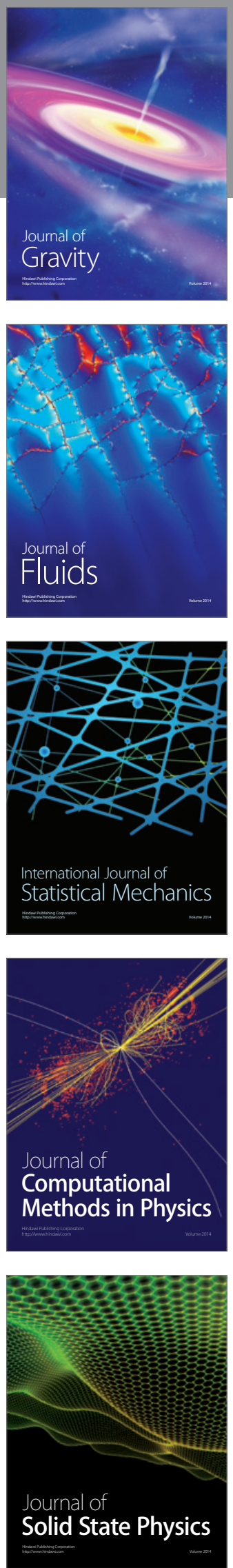

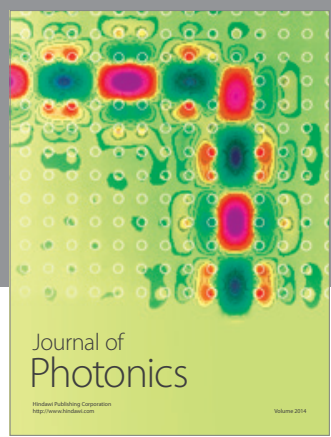

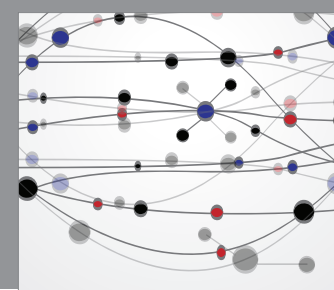

The Scientific World Journal

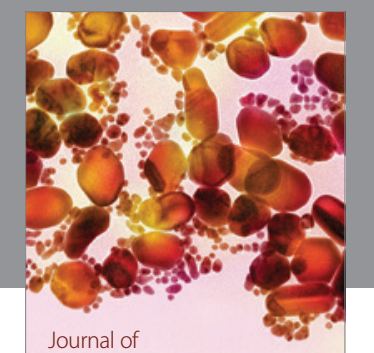

Soft Matter
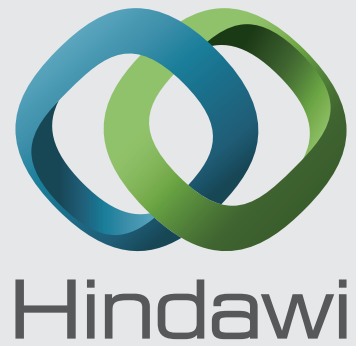

Submit your manuscripts at

http://www.hindawi.com
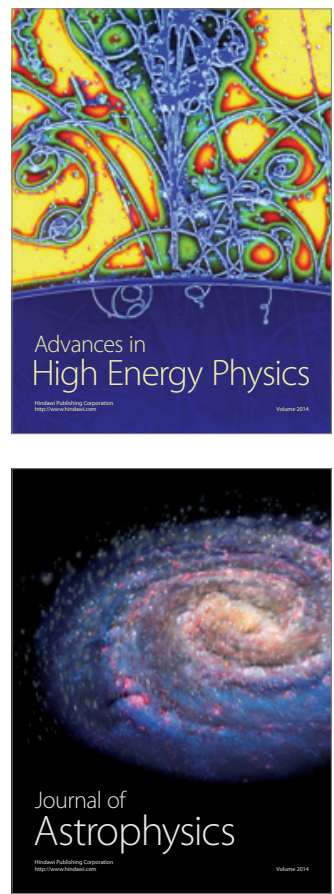
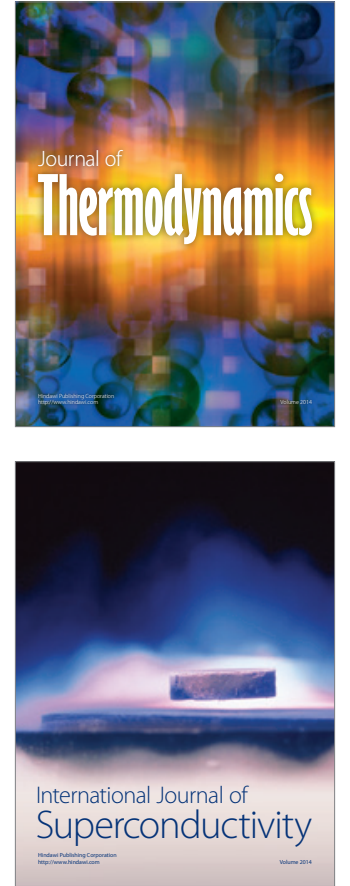
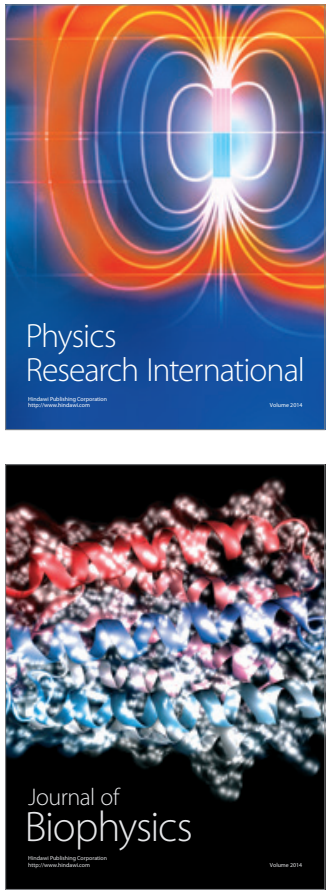
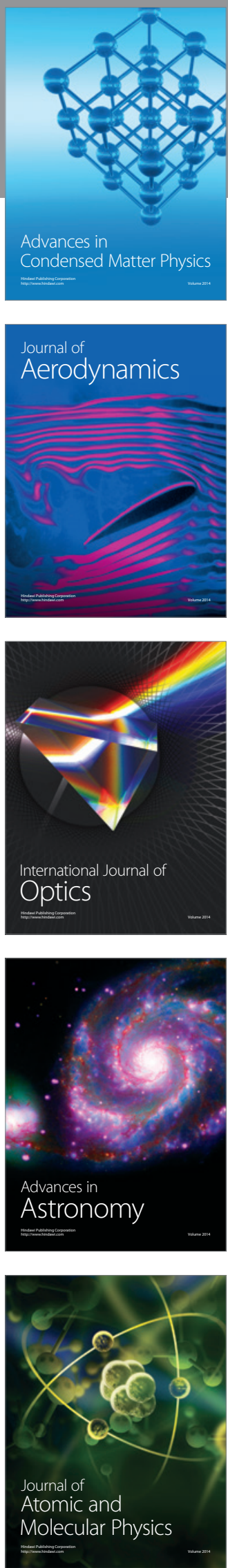